\title{
A Study on the Strategy of Chinese-English Consecutive Interpreting of Beijing Historical and Cultural Speeches
}

\author{
Hairuo Wang \\ School of Foreign Languages, North China Electric Power University, Beijing, China \\ Email address: \\ wanghairuo@aliyun.com,188285439@qq.com
}

\section{To cite this article:}

Hairuo Wang. A Study on the Strategy of Chinese-English Consecutive Interpreting of Beijing Historical and Cultural Speeches. International Journal of Applied Linguistics and Translation. Vol. 2, No. 5, 2016, pp. 43-52. doi: 10.11648/j.ijalt.20160205.11

Received: May 2, 2016; Accepted: September 23, 2016; Published: October 14, 2016

\begin{abstract}
Historical and cultural speeches are considered a challenge in Chinese to English interpretation, as each language describes the world in a different way. Therefore, Beijing historical and cultural speeches are believed to have high level of difficulty in terms of interpretation. This study was aimed at investigating the strategies used in interpreting Beijing historical and cultural speeches. Based on the literature review, two models of interpretation are established, and three cases of interpreting strategy of Beijing historical and cultural speeches based on the models are analyzed.
\end{abstract}

Keywords: Beijing Historical and Cultural Speeches, Interpreting Strategy Model, Interpreting Strategy

\section{Introduction}

In interpreting practice and students interpreting education, it is generally believed that historically and culturally specific topic is difficult, thus challenging both the ability to inculcate one language into another in accordance with the translation standard as well as the limited processing capacity that is the inherent nature of interpreting featured with immediate communication. This is true, especially for the interpretation of speech from Chinese into English; two languages describing the world in different ways. However, with the ongoing globalization process, people from various countries now have in-depth understanding of each other when communicating, and since there is much need for interpreting Chinese historical and cultural speeches into English, it is a necessity to study the strategy of interpretation in order to provide some references in teaching Chinese-English interpretation and facilitate bilingual communication.

This paper was aimed at exploring the possible challenges of interpreting consecutively the Chinese cultural and historical speeches into English and tries to work out an applicable model of interpreting strategy in the training of interpreting students.

The aim of this study can be further broken down into three questions. Questions: 1. What are the potential challenging points in Chinese-English consecutive interpreting of Beijing historical and cultural speeches? 2. What are the possible strategies to meet the challenges in interpreting Beijing historical and cultural speeches? 3. To what extent are the strategies viable in interpreting practice and student exercise? This study tries to discuss the three questions.

\section{Literature Review}

\subsection{Model of Consecutive Interpreting}

Gile (2009) developed the Effort Models of both simultaneous interpreting and consecutive interpreting based on cognitive psychology in order to shed some light on the possible strategies in interpreting. According to Gile (2009: 163-165), there are two phases of consecutive interpreting.

"Phase one: listening and note-taking

(8) Interpreting $=\mathrm{L}+\mathrm{N}+\mathrm{M}+\mathrm{C}$

L: Listening and Analysis

$\mathrm{N}$ : Note-taking

M: Short-term Memory operations

$\mathrm{C}$ : Coordination

Phase two: target-speech production

(9) Interpreting $=\mathrm{Rem}+\mathrm{Read}+\mathrm{P}+\mathrm{C}$

Rem: Remembering

Read: Note-reading

P: Production"

In order to have a smooth consecutive interpreting, the following conditions should be met. 
“(10) $\mathrm{LR}+\mathrm{NR}+\mathrm{MR}+\mathrm{CR} \leq \mathrm{TA}$

(11) $\mathrm{LR} \leq \mathrm{LA}$

(12) $\mathrm{NR} \leq \mathrm{NA}$

(13) $\mathrm{MR} \leq \mathrm{MA}$

(14) $\mathrm{CR} \leq \mathrm{CA}$

TR: Total processing capacity requirements

LR: processing capacity requirements for $\mathrm{L}$

MR: processing capacity requirements for $M$

PR: processing capacity requirements for $\mathrm{P}$

$\mathrm{CR}$ : processing capacity requirements for $\mathrm{C}$

TA: total available processing capacity

LA: the processing capacity available for $\mathrm{L}$

MA: the processing capacity available for $M$

$\mathrm{NA}$ : the processing capacity available for $\mathrm{N}$

CA: the processing capacity available for C"

"When inequality (10) is not true, saturation can occur. When inequalities (11), (12), (13) or (14) are not true, failure may result in spite of the possibility of total available capacity being larger than total requirements." (Gile, 2009: 165) The implication of this model is that when the total required capacity does not exceed the total available capacity and each part of the required capacity does not exceed the available capacity, it is possible that the consecutive interpreting can proceed smoothly. Otherwise, consecutive interpreting may fail.

This observation is important for the development of interpreting strategy since it may lead to one conclusion: the economy of each part of the total processing capacity is very important for the successful process of consecutive interpreting. A question then follows: what leads to the saturation of the processing capacity? In Gile's work, that is called "problem trigger"; while in some other studies, it is called "errors".

\subsection{Problem Triggers and Error Analysis}

Problem triggers, under the conceptual framework of the Effort Models, are considered to be "associated with increased processing capacity requirements which may exceed available capacity or cause attention management problems, or with vulnerability to a momentary lapse of attention of speech segments with certain features" (Gile, 2009: 171). Problem triggers may include names, numbers, enumerations, fast speeches, strong foreign or regional accents, poor speech logic, poor sound, etc. (Gile, 2009: 171).

Relevant studies try to find out the problems triggers and why. Gile (1999) conducted an empirical study and found out that when 10 professional interpreters interpret the same speech twice in a row in the same external environment, many errors and omissions found at first were corrected in the second time, while some new errors and omissions occurred in the second set of interpretations. The only plausible explanation is that the processing capacity of each interpreter is limited and therefore, attentional resources are not adequately allocated or available. Matysiak (2001, cited in Gile 2009: 183) and Gile (2009: 183) replicated the experiment and found similar results. Gile (2001; 2009: 183) predicted the specific difficulties in simultaneous interpreting versus consecutive interpreting in the same speech on the basis of the Tightrope Hypothesis and found errors and omissions consistent with the hypothesis. Some studies reported indirect evidence on numbers, names and idiomatic expressions as problem triggers for their neighboring segments (Gile, 2009: 183; Mazza, 2000; Cattaneo, 2004). Liu and Xiao (2010) conducted a study on number errors based on the corpus of a DAVOS conference and drew the conclusion that interpreting on number is a challenge in English-Chinese simultaneous interpreting. The main reasons for the errors are believed to be the speech made by the speaker being too fast, numbers coming together, and the contexts of the number being incomprehensible to the interpreter.

Wang (2015) conducted a study of errors of consecutive interpreting of students with Chinese and English language pairs with the corpus of the finals of 3rd CTPC Cup All China Interpreting Contest. The errors of Chinese to English (C-E) were separately examined from those of English to Chinese (E-C).

Based on the analysis of both C-E interpretation and E-C interpretation, three hypotheses were accepted. (1) Numbers can be problem triggers for students in consecutive interpreting. (2) Nouns (or names) can be problem triggers for students in consecutive interpreting. (3) Logical relationship can be a problem trigger for students in consecutive interpreting. It is also evident that the logical relationship constitutes a much more prominent problem trigger than nouns. Presumably, it is important for the teacher to emphasize on the identification of the logical relationship to the students during the training process.

\subsection{Concepts}

Concepts, mainly reflected in lexis, can reflect extra-textual factors and intra-textual factors of the text. (Nord, 2005: 122-129)

"For example, the semantic and stylistic characteristics of lexis (e.g., connotations, semantic fields, register) may point to the dimensions of content, subject matter, and presuppositions, whereas the formal and grammatical characteristics (e.g., parts of speech, word function, morphology) refer the analyst to predictable syntactic structures and supra-segmental features." (Nord, 2005: 122)

This is of interest to the interpreting strategy as lexis or concept is what the interpreter is able to perceive directly. And with the understanding of the lexis, features of the text can be detected.

\subsection{Information Structure}

Halliday (2008: 89) believed that information unit is a structure made up of two functions namely, the New and the Given. "The significant variable is: information presented by the speaker as recoverable (Given) or not recoverable (New) to the listener. What is treated as recoverable may be because it has been mentioned before; but that is not the only possibility. It may be something in the situation, such as you and I; in the air, so to speak; or something not around at all but 
that the speaker wants to present as Given for rhetorical purposes.

Similarly, what is treated as non-recoverable may be something that has not been mentioned; and may be something unexpected, whether previously mentioned or not." (Halliday, 2008: 91)

In interpreting, some concept, when the speaker, already mentions it even in the most careless way, should be seen as given information. And some information that can be inferred from the context or is the common knowledge between the speaker and the listener, should be seen as given information. This is significant to the interpreting strategy.

\subsubsection{Information Structure on Textual Dimension}

There are many studies on the classification of the text types, of which Jones (2008) was one whose classification focus particularly on the text types in interpreting. Jones (2008: 14-21) believed that there are four types of text and several sub-types of speeches. Admittedly, this classification may not be exhaustive, but it does consist some of the most common types interpreters may encounter in their practice. (1) Reasoned logical argument - Jones believed that there are two sub-types to this classification: (a) exhibiting the viewpoints of two parties, giving analysis to the two and drawing a comprehensive conclusion; (b) drawing the only plausible conclusion the speaker believes by a series of reasoned logical argument. (2) Narrative speeches with chronological order This includes the description of an event, a scene or a detailed presentation of data. (3) Persuasive speeches - The purpose of this type of speech is to persuade the listener. (4) Rhetorical speeches - The purpose is to impress the listeners with elegant style and broad scope of knowledge; viewpoints may be hinted in the speech.

One of the purposes for identifying those text (speech) types is to apply different strategies. Jones (2008: 15-21) proposed different strategies for those text types. Firstly, If the speaker is making logical argument, whether it is one side or two sides of the viewpoint, the interpreter should pay special attention to the logical connections, especially the connective words, such as "but, however, on the other hand, as, given that, therefore, consequently, because, thence", etc. And those logical connective words are very important indicators for the development of the speech. This is due to the rigorous logic, from $\mathrm{A}$ to $\mathrm{B}$ to $\mathrm{C}$, any mistake or omission by the interpreter could collapse the structure, which translates to unintelligible speech for the listener relying on the interpretation. Therefore, the interpreter should focus on all logical connective words. The second type, chronological narrative speeches could be a story or history. Listeners could be expecting to know when something happen; therefore, the interpreter should focus on temporal phrases, date and verb tense. The third type, descriptive speech, could involve enumeration of many items, which do not necessarily relate to each other; in this case, the interpreter could try to identify the important message and interpret accordingly. The fourth type, rhetorical speech, is challenging due to its complicated form and style. Speakers may use metaphor, simile, etc.; to impress the listener. In this case, interpreter should mobilize all possible resources of the source and target language in order to interpret. If the rhetorical speech is not about expressing any ideas, the interpreter should follow closely in order to avoid adding any idea that is not mentioned by the speaker.

Jones (2008) discussed the general strategy from the perspective of the text type, which should be a starting point of the strategies applied in interpreting.

\subsubsection{Information Structure on Theme-Rheme Dimension at Approximately the Sentence Level}

Text type is a very important level of strategy planning in interpreting. However, interpreting, unlike translation, which allows the translator to access the whole text, only allows the interpreter to work on the incoming message. Therefore, to make the strategy work, it is important to find out the strategy at the operational level of interpreting, which is at a micro-level.

Nord (2005: 115) believed that in oral texts, sentence is marked by phonetic devices (such as high pitch or long pauses). And whether it is grammatical complete is not the criteria of a sentence. Sentence can be an approximation of the micro-level structure of the text. The key is to try to determine whether the sentence, form-based partition, is in line with semantic information unit. The division based on information unit or semantics is called theme-rheme. (Nord, 2005: 116-117) It can also be called topic-comment. This is a micro-structure, which is independent of syntactic structure. With the progression of the theme and the connective by devices, macro-structure can be formed. Therefore, theme-rheme structure is where micro-structure and macro-structure meet.

Theme-rheme division seems to be an appropriate choice for analyzing interpreting strategy because the operation of interpreting can hardly work if an interpreter constantly reminds himself/herself of what is the subject or predicate, as in the division of school grammar. And it seems that interpreting work better on a semantic level. Therefore, the semantic division of the sentence into theme and rheme instead of subject and predicate using grammatical standard may work better for interpreting strategy.

Theme is, more often than not, what is at the beginning at the sentence while rheme is what follows the theme in the sentence (Hu, 2012: 12; Halliday, 2008: 64). Baker (1992: 121-122) believed that theme-rheme division is a way of analyzing the interactional structure of a sentence. According to Baker, there are two major functions of theme. Firstly, it connects to the previous discourse, pointing out the direction of progression. Secondly, it serves as a starting point to connect the previous parts and make contribution to what comes next. And rheme is what the speaker wants the listeners to know. It is rheme that realize the communicative purpose.

The theme-rheme division developed by Halliday is applicable to both English and Chinese as the latter was the first language Halliday investigated in detail (Martin et al, 2010: 1). Many scholars believed that theme-rheme division can be used in describing the characteristics of Chinese (Fang, 
1989; Liu, 2010; Cao, 2011; Baker, 1992: 141). Some scholars made detailed analysis on the difference between theme-rheme and topic-comment of the Chinese language. However, since this study was aimed to explore the possible interpreting strategy, focusing mainly on the semantics and information flow, and not grammatical detail, this paper will only consider theme-rheme as the generic way of division of the sentence.

The theme is seen as the Given information while the rheme as New information. (Halliday, 2008: 93) In translation, rheme, because it is the new information (something the speaker would want the listeners to know in the discourse) is the core of the information. (Baker, 1992: 131-132) This is not only significant to translation, but also to interpreting. This implies that the interpreter should focus on the information of the rheme in order to convey the message.

Based on the distribution of the Given and New information in the text, there are different structures of thematic progression (Daneš, 1978: 188; Nord, 2005: 117). There are mainly three basic structures of theme-rheme. (1) If the communicative dynamism of a text is linear, which means the rheme of the previous sentence becomes the theme of the next sentence; the structure of thematic progression is " $\mathrm{R} 1--\mathrm{T} 2$ ". (Tan, 2001: 15) (2) The theme of the previous sentence continues to be the theme of the next sentence, which means one theme with several rhemes, with the structure of "T1--T2". (Tan, 2001: 15) (3) The theme of the sentence combines with the rheme to be the theme of the next sentence, with the structure of "T1+R1--T2". (Tan, 2001: 16) These three thematic structures are the most basic, which could develop more complicated theme-rheme structures. (Zhu, 1997: 12; $\mathrm{Hu}$, 1994: 144-145) In interpreting, these three types of thematic structures are with different levels of difficulty. Therefore, different strategies may be applied.

\section{An Interim Model of Consecutive Interpreting of Beijing Historical and Cultural Speeches}

Based on the analysis above, texts type, theme-rheme structure, and concept are all the factors of the speech delivered by the speakers that could be detected directly by the interpreter. They could also all play a role affecting the strategy of interpreting. In this section, the author will establish an interpreting strategy model and try to analyze the strategy accordingly.

\subsection{Interpreting Strategy Model in General}

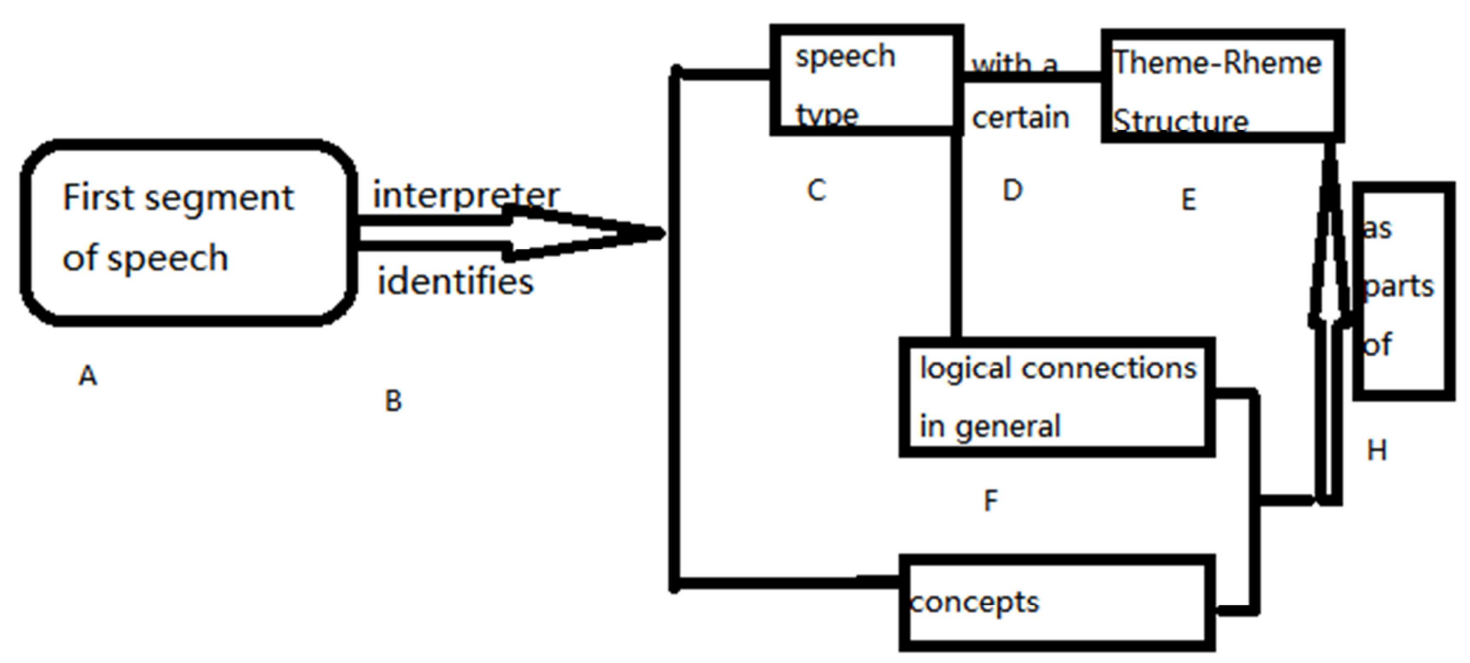

G

Figure 1. Consecutive Interpreting Strategy in General.

The general idea of this model is to develop a model of interpreting strategy that makes the passive reception of input of the speaker into an active strategy on the part of the interpreter by detection of the speech type, theme-rheme structure, logical connections and concepts. This implies that, however brief and rough it might be, the interpreter can have certain strategy planning for the incoming segment of speech. One assumption of this model is that the conversion of the speech into another language happens almost at same time with the listening. And consecutive interpreting only allows the production of the interpreted speech to be made later when it is the turn of the interpreter.

Box A indicates the first segment of the speech for the interpreter to identify the speech type, theme-rheme structure and concept. Since this is not just about an exercise of listening comprehension, the interpreter should be able to interpret at the same time. Therefore, identifying the three elements should also be a process of interpreting, and being able to reflect those in the interpretation.

However, this is only an ideal model of interpreting strategy, with only acoustic input to the interpreter, without considering the environmental and situational input, whereas in reality, the 
interpreter may have access to other resources, such as speech draft, slides, etc.

In theory, "First segment of speech" can be of any length before the speaker gives the turn to the interpreter. However, the shorter this "first segment", the quicker the interpreter will be in an active state of interpreting the speech. Of course, if the "first segment" is too short, it may not truly reflect the whole picture of the speech. Thus, it may involve much risk on the part of the interpreter to make judgment too soon. Therefore, the interpreter may be constantly sensitive to the information flow.

While the interpreter is detecting the speech type and theme-rheme structure, he/she is also constantly monitoring the logical connections, which, together with Box G--concept, form the theme-rheme structure.

In reality, it is possible to get to know the speech type beforehand by getting to know the nature of the conference and the title of the speech, which greatly lowers the effort of identifying the speech type. It is also possible to lower the effort of identifying concept by previewing relevant conference materials, such as drafts or outlines of speeches, slides of the speakers, papers of the conference, etc. The preparation can be done before the speech is delivered, even before the conference. This gives room for more processing capacity, which can be focused on dealing with logical connections in general and theme-rheme structure.

\subsection{Detailed Consecutive Interpreting Model}

While Figure 1 illustrates a model of consecutive interpreting strategy in general, Figure 2 presents a more detailed model of consecutive interpreting strategy.

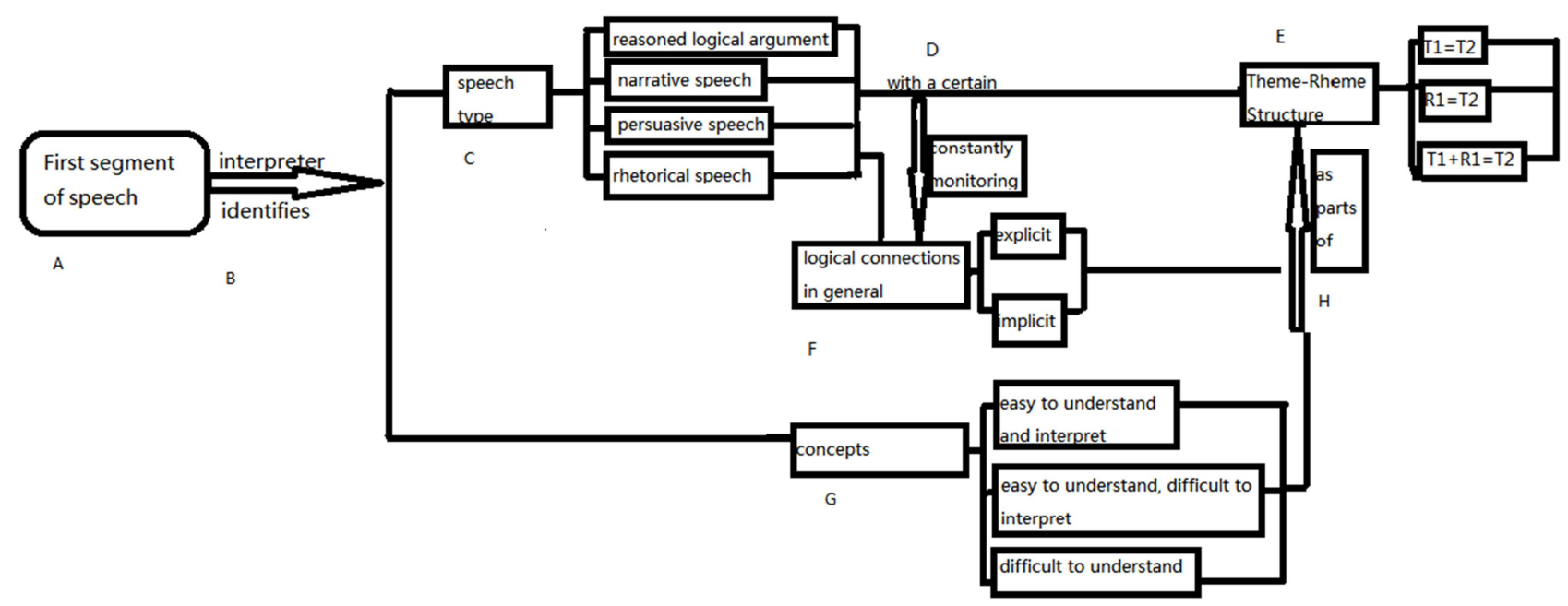

Figure 2. Detailed Consecutive Interpreting Strategy.

The basic framework of the detailed model is the same as the previous one, while more details of each box are included in the model, which may be helpful in shedding some light on the plan of interpreting strategy.

In this model, the Box C--speech type--is followed by detailed types according to the classification of Jones (2008), i.e., reasoned logical argument, narrative speech, persuasive speech, and rhetorical speech. Box E--Theme-Rheme structure--is followed by the three types discussed in the previous section, i.e., T1--T2, R1--T2, and T1+R1-T2. And Box F--logical connections in general is followed by two types of logical connections: Explicit logical connective words, such as "because", "as a result", etc. The other type of logical connection is implicit, which could happen in the Chinese language featured with connection by the sense instead of connective words. Box G--concepts--is followed by three basic types of concepts, the classification is relevant to the consecutive interpreting strategy: (1) easy to understand and interpret, which happens to some of concepts that belongs to common knowledge; (2) easy to understand, difficult to interpret, which happens a lot to some of the culturally specific items; (3) difficult to understand, which happens to some professional concepts or difficult terms as common knowledge to the speaker and listener but perhaps unknown to the interpreter.

\subsection{Strategy Analysis Based Upon the Models}

The key to the strategy of interpreting is to "juggle" each part of the processing capacity in Gile's Efforts Model in order to keep a balance of the total available capacity. In this sense, some proposals to try to minimize the required processing capacity can be made based on the models of consecutive interpreting in this paper and Gile's Efforts Models.

To be fully prepared before the interpreting process can be very important. This includes analyzing the title of the speech to identify the possible speech type, and figuring out the key concepts with the slides, outline of the draft of speech, etc. In this way, the required processing capacity for Box A and Box $\mathrm{G}$ can be greatly reduced, leaving more available capacity to Box $\mathrm{F}$ and Box E.

When some concept, or other message, once said by the speaker, however downplayed, is no longer new information. Therefore, the interpreter, especially student interpreter, 
should be fully aware of it, and get used to this as quickly as possible. For instance, some repeated concept should be interpreted properly by the interpreter upon hearing it for the first time. And when it is repeated, it should not be treated as new information, in order to lower the processing capacity for this piece of information as much as possible. since the production of consecutive interpreting is due only when the speaker completes a section of the speech, there is some time left for the interpreter to deal with the proper interpretation.

More attention should be given to the new information, or the rheme. Because rheme is what follows theme, and because the interpreter waits until the speaker finishes in consecutive interpreting, it is possible for the interpreter to focus on rheme.

When the concept of the speech is easy, more attention should be given to the logic of the speech. This is not only about the general logic, but also the local logic.

When the concept of the speech is difficult, more attention should firstly be given to the understanding and interpretation of the concept in order to successfully interpret.

When both the concept and the logic of the speech are difficult, more attention should be given to the logic in order to follow the speaker.

\section{Strategy Analysis of the Cases of Beijing Historical and Cultural Speeches Based Upon the Models}

The models and strategies proposed in this paper can be applied to Beijing historical and cultural speeches. There are three cases as follows:

Case 1

${ }^{1}$ 这个亭子呀, 它四面都开门儿。为什么要四面开门儿 呢? 你可以想象一下, 如果一个方块儿里面没有门, 里边 放一个人字是什么字啊? 囚。囚是吧, 那皇帝肯定不希望 自己作为一个囚犯来生活, 所以说他要在四面儿都开门儿, 打开以后呀, 四面通风。那么, 它真正的作用是做什么的 呢? 刚才我们说了, 皇帝呀他在举行大朝礼的时候, 他是 直接上前面儿吗？他从后宫...台...台上走前边儿来以后, 他会在那个地方先稍事休息啊, 在那里面喝杯茶。那个明 朝大朝礼的时候那些个礼仪官员儿啊, 都下趾着。

(1) Information structure analysis

The first case is a speech of a tour guide briefing visiting school children on the story of the Forbidden Palace. The general difficulty level is low.

The structure of the first several sentences is as follows.

\begin{tabular}{|c|c|}
\hline 这个亭子呀 & 它四面都开门儿 \\
\hline $\mathrm{T} 1$ & $\mathrm{R} 1$ \\
\hline 为什么 & 要四面开门儿呢 \\
\hline $\mathrm{T} 2$ & R2 \\
\hline 你 & 可以想象一下 \\
\hline $\mathrm{T} 3$ & $\mathrm{R} 3$ \\
\hline
\end{tabular}

T4

如果一个方块儿里面没有门 里边放一个人字是什么字啊

1 This is a transcript based on a video from the webpage http://v.17173.com/v_102_614/MTczODEyNzk.html, retrieved on Feb. 10, 2016
$\mathrm{T} 5$ R5

$$
\text { R4 }
$$

(2) Analysis of the strategy

Based on the consecutive interpreting model, firstly, this is detected to be a narrative speech upon hearing the first segment. It seems that the concepts in the speech are easy to understand and interpret, with much environmental information as clues. Therefore, it is possible for the interpreter to focus on the "new information" and the logic of the speech.

It is noticeable that $\mathrm{R} 1 \approx \mathrm{R} 2$. However, there are a number of different rhemes, indicating much new information in the speech centered on the topic of the layout of the pavilion. The sentences are mainly short and very different from idiomatic English structure. Thus in consecutive interpreting, the strategy could be focused on understanding the logic of the speech and the production accordingly in a relatively idiomatic way in English, arranging the production according to the typical English theme-rheme structure.

If necessary, it is possible to leave out certain less important details or what can be inferred. For instance, “打开以后呀, 四面通风” literally translated, as "When they are opened, draught is able to come in from the four directions". "When they are opened" can be inferred from the context because only by doing so can draught comes in from the four directions. Therefore, this can be left out.

(3) Comments on the strategy

This type of Beijing historical and cultural speech featured a typical Chinese language, with short sentences and lots of rhemes; this speaker asked questions severally to maintain interaction with the listeners. If the interpreter is to preserve the original Chinese "taste" of the short sentences and follow the speaker's style of maintaining interaction while interpreting, then the production may not sound like idiomatic English. In consecutive interpreting, it is possible to "sort out" more idiomatic English because the interpreter gets the chance to listen to a complete segment of the speech. Of course, it is possible that certain occasions require the preservation of this Chinese "taste" and the interactive sense if the speaker waits for the interpreter to take the turn.

Case 2

${ }^{2}$ 唐朝外戚之祸也很厉害。下面我说唐朝。唐朝最著名 的就是武则天了。武则天用娘家人外戚呀, 后来发生了一 个大的变局。诛武氏, 跟武氏有关的。武则天这个人我不 作评论了啊。但是她有些话说的太值得思考了。我就例举 这三句话。第一句话, “爵位富贵朕所予也”。你们的官呀, 你们的富贵, 都是我给你们的。...你们听我不听我的? 第 二句话说: “天下安佚朕所养也”。天下老百姓你安居乐业 过得很好, 都是我养着你呀! 你本末倒置了, 天下养的你 呀, 怎么会是你养天下呢? 第三句话说: “不利于朕朕能 戮之”，朕可以杀了你。典型的封建集权的这种专制。她 要取得实际权力就用她的武家的人引起一个更大的宫廷 变乱。结果是个什么情况呢? 结果是外戚武家遭到历史的

2 This is a transcript based on a video from the webpage http://tv.cntv.cn/video/C10302/607ac2f7ad9e4cba80b15b3c8d92e100, retrieved on Feb. 17, 2016. 
报复。“斫棺暴尸平其坟墓”。把棺材给䢃了, 坟挖了, 棺 材䢃了, 暴尸原野, 最后武家得到这么一个结局。

(1) Information structure analysis

This second case is a scholar giving a historical lecture to the TV audience on the consort kin. This is more difficult compared with the first case. However, the main speech type was narrative, story-telling. Therefore, the difficulty level is medium.

The structure of the first several sentences is as follows.

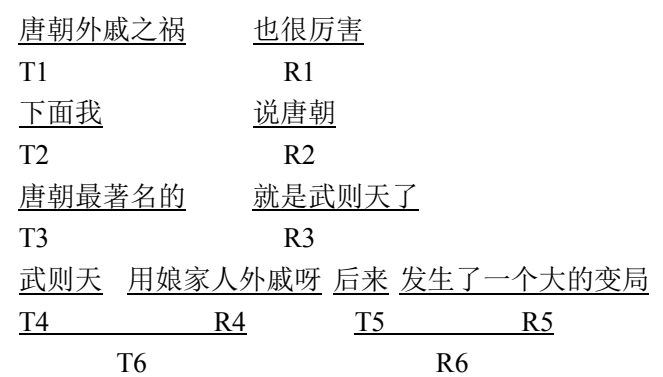

(2) Analysis of the strategy

Based on the consecutive interpreting model, similar to Case 1, this case is also a narrative speech of Beijing culture and history upon hearing the first segment. The concepts are relatively more difficult than in Case 1, which implies that more attention or processing capacity needs to be allocated to the understanding of the concepts.

In the first several sentences, $\mathrm{R} 3 \approx \mathrm{T} 4$, there are many different themes and rhemes, with implicit logical connections. In this segment of the speech, there is a lot of ancient Chinese quotation, followed by an explanation by the speaker. Only one of the two (explanation and quotation) is required to be interpreted since the explanation is virtually the same as the quotation. In effect, it relieves much of the processing capacity.

Similar to Case 1, the segment of the speech is featured with short sentences and many rhemes, to interpret them into idiomatic English; information on several sentences could be gathered into one sentence.

(3) Comments on the strategy

The way the speaker delivers the speech represents a traditional structure of academic explanations on historical issues, by foreshadowing the topic and illustrating with relevant historical texts with explanation and interpretation of the text. The structure of illustration is quite different from the English textual structure, and may be difficult to listeners without prior knowledge of the Chinese language. However, there seems to be few ways of adapting the whole structure of the text interpretation except for minor adjustment of the order of phrases and clauses in the sentence. It seems that what the interpreter is able to do is to work hard at the sentence level and try to make every sentence as clear as possible.

Case 3

3 通过大遗址保护和考古遗址公园建设实践, 我们得出 三点体会: 一是新时期文化遗产应该拥有尊严, 今天这些 书画、铜器、玉器、瓷器等可移动文物, 已经被人们认识 到其对于现实生活的文化意义, 精心加以保护。这些古代

3 Extracted from Shan (2014).
建筑、考古遗址、历史街区、历史村镇等不可移动文物, 也应该使广大民众认识到其对于现实生活的文化意义, 使 他们成为城市中最美丽、最令人向往的地方, 给人们带来 精神愉悦和文化灵感的地方。只有这样, 文化遗产才能拥 有尊严。二是文化遗产事业应该融入经济社会的发展, 不 能仅仅把文化遗产保护看做是专业部门、行业系统的工作, 而应该为更多部门和社会民众所理解，通过一件件保护实 践的成果，使文化遗产保护成为促进经济社会发展的积极 力量。三是文化遗产保护成果应该惠及广大民众, 只有当 地民众从文化遗产保护的实践中获得实实在在的切身利 益, 他们才会倾心地拥护、支持、监督、参与文化遗产保 护，文化遗产保护成果才能更大限度地惠及民众。

(1) Information structure analysis

This third case was an academic speech on city construction and preservation of cultural relics given by the Director of the Palace Museum. It featured more abstract concepts and difficult logic.

The structure of the first several sentences is as follows. 通过大遗址保护和考古遗址公园建设实践, 我们得出三点体会

$\mathrm{T} 1$

二是新时期文化遗产

R1

$\mathrm{T} 2 \mathrm{R} 2$ 应该拥有尊严

今天这些书画、铜器、玉器、瓷器等可移动文物

$\mathrm{T} 3$

已经被人们认识到其对于现实生活的文化意义, 精心加以保护

R3

这些古代建筑、考古遗址、历史街区、历史村镇等不可移动文物

T4/T5

也应该使广大民众认识到其对于现实生活的文化意义

R4

使他们成为城市中最美丽、最令人向往的地方, 给人们带来精神愉悦 和文化灵感的地方

R5

(2) Analysis of the strategy

Based on the consecutive interpreting model, upon hearing the first segment of the speech, it is known that the speech type is reasoned logical argument. The concept here is difficult for two reasons. Firstly, there are are many concepts included in this speech segment, some being enumerations, challenging the processing capacity of the interpreter. Secondly, there is a logical relationship between concepts, for instance, some are parallel, such as “书画、铜器、玉器、瓷器”, literally translated as "painting and calligraphy, bronzeware, jadeware, procelain”, and some are subordinate, such as the “书画、铜 器、玉器、瓷器” and “可移动文物”, literally translated as "painting and calligraphy, bronzeware, jadeware, procelain" and "portable antiquities". Thus, understanding the concept is very much relevant to understanding the logic in this case.

It is possible that not all concepts in enumeration are interpreted because of the limited processing capacity. As "painting and calligraphy, bronzeware, jadeware, procelain" are parts of "portable antiquities", the latter should be strategically more important in interpreting.

Analyzing the theme-rheme structure, it is found that T2, $\mathrm{T} 3, \mathrm{~T} 4 / \mathrm{T} 5$ are mainly the same thing, indicating cultural relics. Therefore, there is a focused theme with several different rhemes; the information structure is relatively easy to grasp. 
(3) Comments on the strategy

The structure of this example is basically in line with English textual structure of reasoned logical argument. The structure may be easier for the listener to understand, as the structure is familiar. What is difficult is that the relationship between concepts is abstract, same with logic, which requires the interpreter to be able to understand the more abstract terms and logic.

\section{Findings and Discussions}

Based upon the analysis of the models and cases, several findings can be discussed as follows.

The Models can only be served as reference and they illustrate the general principle of interpreting strategy. Application of the Models and strategies should be dependent upon concrete cases.

The key for the strategy of consecutive interpreting is to minimize the required processing capacity as much as possible In other words, it is to try to minimize the required processing capacity at any given point as much as possible.

In the analysis of the models and the cases, it was found out that there are several things the interpreter can do to reduce the required processing capacity at any given time. For example, the Beijing cultural and historical speeches are featured with culturally specific items, which may require much processing capacity. What's more, those culturally specific items may not be properly anticipated in the process of interpreting. Therefore, in order to reduce the processing capacity needed, preparation beforehand is a must.

Based on the analysis of the cases, it seems possible that abstract terms go hand in hand with more complicated logic, which makes it exceptionally challenging. Therefore, it is necessary for the interpreters to make continuous improvement on the understanding of the logic of various different speeches.

The theme-rheme structure is one of the three basic types. However, the structure proposed here is only a means of identifying the given and the new information. In the case of the interpreter, it is not necessary to know exactly what belongs to the theme or the rheme in practice; only a focus on the new information is required.

It seems that the narrative speeches of Beijing history and culture is far more than just a difficult concept. The thematic structure is too complicated, with different rhemes in short sentences, a prominent feature of traditional Chinese language. In interpreting, though little room is left for the interpreter who has to make an interpreting decision on the spot, it is a must to interpret to an acceptable English, at least at the sentence level.

In the case of the academic speech of Beijing history and culture, presumably, it is more difficult than the narrative speech, with more abstract terms and logic. However, the thematic structure is clear and close to those in English structure. Therefore, with adequate comprehension ability, it can be less difficult to interpret, while focusing on and paying attention to the concept and logic.

\section{Conclusion and Limitations}

The questions asked at the beginning of the paper were: 1 . What are the potential challenging points in Chinese-English consecutive interpreting of Beijing historical and cultural speeches? 2. What are the possible strategies to meet the challenges in Beijing historical and cultural speeches? 3. To what extent are the strategies viable in interpreting practice and exercise?

Table 1 presents an illustration on the three questions.

Table 1. Challenges-Strategies-Viability.

\begin{tabular}{|c|c|c|}
\hline Challenges & Interpreting strategies & Is it viable in practice? \\
\hline Concept easy, logic easy & Focus on logic & $\begin{array}{l}\text { Yes. Whether the concept is easy or not can be directly perceived by the } \\
\text { interpreter. }\end{array}$ \\
\hline Concept difficult, logic easy & $\begin{array}{l}\text { Focus on concept first } \\
\text { Leaving out less important details }\end{array}$ & $\begin{array}{l}\text { Yes. (1) It would be better if the concepts can be prepared beforehand. (2) } \\
\text { Leaving out what can be inferred from the context can save the interpreter } \\
\text { some processing capacity. }\end{array}$ \\
\hline Both concept and logic difficult & Focus on logic first & $\begin{array}{l}\text { Yes. Concept is a part of the logical structure. Therefore, if logic in general } \\
\text { is understood, it is more likely to find ways to interpret the concept. }\end{array}$ \\
\hline $\begin{array}{l}\text { Chinese thematic structure, with many } \\
\text { rhemes, marking new information. }\end{array}$ & Focus on rheme & Yes. Get prepared for the text (speech) type beforehand. \\
\hline $\begin{array}{l}\text { Different Chinese and English textual } \\
\text { structures, making it difficult for } \\
\text { listeners to understand }\end{array}$ & $\begin{array}{l}\text { Try to make interpretation very clear } \\
\text { at the sentence level and make } \\
\text { logical connections clearer. }\end{array}$ & $\begin{array}{l}\text { Yes. However, what an interpreter could do is limited. It seems unlikely to } \\
\text { change the textual structure. }\end{array}$ \\
\hline
\end{tabular}

The strategy models are the ideal type of models, without considering the occurrence of interruptions (for instance, the saturation of the processing capacity). Therefore, further refinement of the model is needed in the future.

There are future questions yet to be answered in this study: (1) How to measure the difficulty level of Chinese texts? (2) Can theme and rheme of the Chinese texts correspond with the English in the interpreters' version? (3) What will happen to the models if language ability is a variable, such as the students who are in the process of developing both the language ability and interpreting skills?

\section{Acknowledgements}

Supported by the Youth Project of Beijing Social Science Fund "an Empirical Study of Interpreting Strategies of Beijing Cultural-History Texts" (15WYC078) 


\section{Appendix--Translation of the Cases}

\section{Case 1}

The pavilion opens the doors at the four sides. Why does it have to do that? Imagine this. If a square without doors has a person in it, what Chinese character does it form? The character "qiu", literally means "prisoner", right? Of course the emperor does not want to live as a prisoner, therefore, he wants the door open at the four sides. When they are opened, draught is able to come in from the four directions. But, what is its real purpose? Just like what is said, when the emperor was holding grand ceremonies, did he just go up to the front? Actually, he came from the back of the palace to the front, having a rest for a while and enjoying a cup of tea there. The protocol officers were all on their knees at the grand ceremonies in Ming Dynasty.

Case 2

Tang Dynasty also suffered heavily from the disaster of the consort kin. Next I am going to talk about the Tang Dynasty. The most famous person of the Tang Dynasty was WU Zetian. Wu Zetian gave important posts to the people of her parents' family, the consort kin. Later, there was a turbulent situation changing. Killing WU, something relevant to WU. I am not making comments on the person WU Zetian. However, she said words that are worth aftertaste a lot. I am giving you three examples. The first sentence is "it is me who give you official posts and wealth." Then, are you obedient to me or not? The second sentence is "people under the sun live and work in contentment. It is me who provide for you." You put the cart before the horse. It was people under the sun who provided for you. How come that you provided for the people? The third sentence is "I can kill those who go against me." That shows typical autocracy of centralized feudal monarchy. When she wanted to get the real power, she took advantage of the people of the WU family to make a bigger upheaval in the court. What was the result then? The result was that the WU family, the consort kin, was retaliated by the history. Coffins were cleaved. Corpse were exposed. Tombs were exhumed. That was the ending of the WU family.

Case 3

There are three takeaways from the practice of preservation of the great ruins and the construction of archaeological parks. Firstly, cultural heritage deserves respect in this new era. The portable antiquities, such as painting and calligraphy, bronzeware, jadeware, and procelain, have been recognized for the cultural significance in real life and carefully protected. People should also be aware of the cultural significance of the immovable cultural relics such as ancient architecture, archaeological site, historical streets and historic towns and villages. And they should be made the most beautiful and desirable place in the city, bringing about spiritual pleasure and cultural inspiration. Only in this way can the cultural relics get respect. Secondly, the work of cultural heritage should be included in socio-economic development. Preservation of cultural relics should not just be treated as the job of some professional sector and industry. It should be understood by more sectors and the general public. Through the achievements of preservation practice, preservation of cultural relics should be made into a positive force promoting socio-economic development. Thirdly, the achievements of preservation of cultural relics should benefit the public. Only when the local people get tangible benefit from the preservation will they be dedicated to the support, supervision and involvement of preservation of cultural relics, which in turn benefit the public even more.

\section{References}

[1] Baker, M. (1992). In Other Words: A Coursebook on Translation. Florence, KY, USA, Routledge.

[2] Cao, H. (2011). "On the Theme and Rheme under the Context of the Chinese Language." Scientific Information (10): 212-213.

[3] Cattaneo, E. (2004). Idiomatic Expressions in Conference Interpreting. SSLMIT, Universita degli Studi di Bologna, Sede di Fiolì.

[4] Daneš, F. (1978). Zur linguistischen Analyse der Textstruktur. Textlinguistik. W. Dressler. Darmstadt, Wissenschaftliche Buchgesellschaft: 181-192.

[5] Fang, Y. (1989). "On the Theme-Rheme Structure of Chinese--and the Comparison with the Theme-Rheme Structure of English." Journal of Tsinghua University (Philosophy and Social Sciences) 4 (2): 66-72.

[6] Gile, D. (1999). "Testing the Effort Models' tightrope hypothesis in simultaneous interpreting--A contribution." Hermes, Journal of Linguistics (23): 153-172.

[7] Gile, D. (2009). Basic Concepts and Models for Interpreter and Translator Training. Amsterdam/Philadelphia, John Benjamins.

[8] Halliday, M. A. K. (2008). An Introduction to Functional Grammar. Beijing, Foreign Language Teaching and Research Press.

[9] Hu, S. Z. (2012). An Introduction to Text Linguisitics. Shanghai, Shanghai Foreign Language Education Press.

[10] Hu, Z. L. (1994). Discourse Cohesion and Coherence. Shanghai, Shanghai Foreign Language Education Press.

[11] Jones, R. (2008). Conference Interpreting Explained. Shanghai, Shanghai Foreign Language Education Press.

[12] Liu, J. H. (2010). "The Comparison Between English Theme Structure and Chinese Topic Structure." Language and Culture Studies (1): 1-4.

[13] Liu, J. J \&Xiao, D. F. (2010). "Number Errors in English-Chinese Simultaneous Interpreting--an Empirical Study Based on the Corpus of 2008 World Economic Forum in Tianjin." Foreign Language Teaching (4): 7.

[14] Matysiak, A. (2001). Controlled processing in simultaneous interpreting: A study based on Daniel Gile's Effort Models, University of Poznan. MA.

[15] Mazza, C. (2000). Numbers in simultaneous interpretation. SSLMIT, Universita degli Studi di Bologna, Sede di Fiolì. 
[16] Martin, J. \& Matthiessen, C \& Painter, C. (2010). Deploying Functional Grammar. Beijing, The Commercial Press.

[17] Nord, C. (2005). Text Analysis in Translation: Theory, Methodology, and Didactic Application of a Model for Translation-Oriented Text Analysis (Second Edition). Amsterdam/New York, Rodopi B. V.

[18] Shan, J. X. (2014). City Cultural Construction and Preservation of Cultural Relics. Historical and Cultural Lectures of Historical Capital of Beijing. B. C. R. P. Association. Beijing, Beijing Yanshan Press: 2-34.

[19] Tan, X. L. (2001). "Some Thinking on Theme and Rheme as Translation Units." Journal of Dandong Normal College 23 (2): 15-17.

[20] Wang, H. R. (2015). "Error Analysis in Consecutive Interpreting of Students With Chinese and English Language Pairs." Canadian Social Science 11 (11): 1-15.

[21] Zhu, Y. S. (1997). "On the Internal Condition of Discourse Coherence (II)." Modern Foreign Languages (1): 12-15.

\section{Biography}

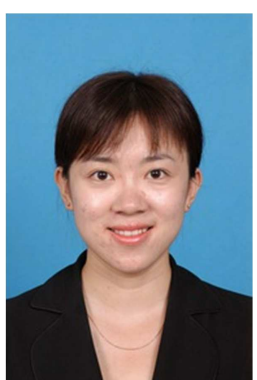

Hairuo Wang got a PhD degree of Interpreting Studies from Shanghai International Studies University. Research interests are mainly on interpreting strategies, roles of interpreters, etc. She is now a Lecturer with North China Electric Power University, conducting four main courses of Basic Interpreting Skills, Consecutive Interpreting, Sight Interpreting and Simultaneous Interpreting for students of the program of Master of Translation and Interpretation. 